\title{
Mitigating Human Impacts on Marine Biodiversity Beyond National Jurisdiction
}

\author{
Potential Benefits of the International Legally Binding Instrument
}

\author{
Robin Warner
}

\begin{abstract}
Environmental impact assessment (EIA) is a critical element in the suite of tools for biodiversity conservation, and its application to activities affecting the marine environment is endorsed in many international law instruments, policy statements by governments and international organisations and the decisions of international tribunals. While governance structures will generally exist to facilitate environmental assessment in marine areas within national jurisdiction closer to the shore, these structures are still developing for marine areas beyond national jurisdiction (ABNJ). This chapter reviews the existing international law and policy framework for EIA in ABNJ highlighting key gaps in legal and institutional coverage at global, regional and sectoral levels. It explores the complex challenges involved in implementing EIA in ABNJ and the steps that have been taken within particular sectors to develop a more comprehensive and robust legal framework for EIA in these extensive areas of the ocean. Finally, it discusses the options for incorporating EIA provisions in the internationally legally binding instrument for conservation and sustainable use of marine biodiversity in ABNJ currently being negotiated in the United Nations.
\end{abstract}

\section{Keywords}

Marine biodiversity - areas beyond national jurisdiction - environmental impact assessment - conservation - marine environment - international law - United Nations Convention on the Law of the Sea - Convention on Biological Diversity

\section{Introduction}

Assessing the impact of human activities on the marine environment introduces additional challenges to those confronted on land. Many of these 
differences stem from the three-dimensional nature of the marine environment with its great depths, pressure and lack of light beneath the photic zone. Others relate to the slow growth rates of many marine organisms leading to delays in recovery from impacts and the extensive interconnections between marine ecosystems compounding the adverse effects of the initial impact. In addition to these physical challenges, there are practical challenges in assessing the impacts of activities which occur in remote locations far from land with scant logistical support.

Notwithstanding these significant challenges, global and regional organizations and national governments have devised some governance structures to underpin the measurement of human impacts on the marine environment. These encompass legally binding instruments at global and regional levels and national legislation supplemented by non-binding guidelines and other policy documents. In addition, customs of practice have developed for environmental assessment in different marine sectors.

\section{2 \\ International Law Framework for Environmental Assessment ${ }^{1}$ in $\mathrm{ABNJ}^{2}$}

Environmental impact assessment is acknowledged as a key element in the suite of tools for biodiversity conservation, and its application to activities affecting the marine environment has been endorsed in many international law instruments, policy statements by governments and international organisations and the decisions of international tribunals. ${ }^{3}$ For ABNJ, however, many of these instruments and decisions discuss general obligations to conduct EIA

1 In this chapter, the term "environmental assessment" is used to refer to all facets of measuring the impact of human activities on the environment. This includes the typical process of prior environmental impact assessment and extends to through and post activity monitoring of environmental impacts. Within those processes the term environmental assessment also encompasses the conduct of environmental baseline studies and the measurement of single as well as cumulative impacts on marine environments over time. Cross jurisdictional application of EIA and strategic environmental assessment (SEA) of plans, programmes, and policies likely to impact the marine environment over longer periods and broader geographical areas are also included in the term environmental assessment.

2 Marine areas beyond national jurisdiction $(\mathrm{ABNJ})$ include both the high seas water column and the deep seabed beyond national jurisdiction (the Area).

3 These instruments include the regional seas conventions, the 1982 United Nations Convention on the Law of the Sea (LOSC), the 1991 Protocol on Environmental Protection to the Antarctic Treaty (Madrid Protocol), the UN Fish Stocks Agreement (UNFSA) and the International Seabed Authority's Regulations for exploration contractors. 
rather than specific implementing provisions or underpinning institutional infrastructure.

\subsection{Global Instruments}

2.1.1 United Nations Convention on the Law of the Sea (LOSC)

The 1982 United Nations Convention on the Law of the Sea (LOSC) imposes a general obligation on States Parties to assess the potential effects of activities under their jurisdiction or control that may cause substantial pollution of, or significant and harmful changes to, the marine environment. Although the general obligation to conduct environmental assessment of activities with the potential for significant and harmful impacts on the marine environment is well established in both customary and conventional international law, implementation of this obligation for marine areas beyond national jurisdiction $(\mathrm{ABNJ})^{4}$ is fragmented between different sectors and regions. There is no overarching international agreement which develops in more specific terms the obligation contained in Article 206 of the LOSC to assess the potential effects of planned activities under States' jurisdiction or control in ABNJ. The LOSC obligations are broad in scope extending to all parts of the marine environment but there are no detailed methodological or procedural requirements specified for environmental assessment in marine and coastal areas. States Parties have a duty to publish reports of assessments to "competent international organizations," but these organizations are not specified and the timescale for provision of reports is not prescribed. Similarly, institutional coverage for ABNJ under the LOSC is far from comprehensive with no global body having overarching responsibility for protection and preservation of the marine environment or conservation of marine biodiversity beyond national jurisdiction. The International Seabed Authority (ISA) has comprehensive environmental protection powers for seabed mining activities affecting the Area, but this advanced environmental governance situation for the deep seabed beyond national jurisdiction is not matched by a global institution with comparable environmental protection powers for the high seas water column. These general obligations to conduct environmental assessment and monitoring under the LOSC must therefore be read in conjunction with the more specific environmental principles and procedural provisions which have been developed in international environmental law instruments such as the Convention on Biological Diversity (CBD) and its EIA-associated guidelines.

4 Marine areas beyond national jurisdiction (ABNJ) include both the high seas water column and the deep seabed beyond national jurisdiction (the Area). 


\subsubsection{Convention on Biological Diversity (CBD)}

The Convention on Biological Diversity ( fundamental obligation of Contracting Parties to conserve biodiversity including marine biodiversity and the conduct of environmental assessment and monitoring. Contracting Parties must introduce appropriate procedures requiring EIA of proposed projects that are likely to have significant adverse effects on biodiversity with a view to avoiding or minimizing such effects (Article $14(1)(a))$. Having identified processes and activities which have or are likely to have significant adverse impacts on the conservation and sustainable use of biological diversity, Contracting Parties are also required to monitor their effects through sampling and other techniques (Article $7(\mathrm{c})$ ). These obligations apply to processes and activities carried out under the jurisdiction or control of Contracting Parties in all parts of the marine and terrestrial environment, regardless of where their effects occur (Art. 4(b)) The critical importance of collaboration between States in minimizing adverse impacts to biodiversity in transboundary areas and areas beyond national jurisdiction is emphasized in Article 14(1)(c) which requires Contracting Parties to promote reciprocal notification, exchange of information and consultation on activities under their jurisdiction or control which are likely to significantly affect adversely the biological diversity of other States or areas beyond the limits of national jurisdiction. In the case of imminent or grave danger or damage, originating under their jurisdiction or control, to biodiversity under the jurisdiction of other States or in areas beyond the limits of national jurisdiction, Contracting Parties must notify immediately the potentially affected States as well as initiate action to prevent or minimize such danger or damage.

The obligations in the СвD have been elaborated in Voluntary Guidelines on Biodiversity-Inclusive Impact Assessment (СвD Guidelines) that emphasize the importance of including biodiversity-related criteria in the screening process. ${ }^{5}$ The Guidelines reflect a best practice standard for E IA s of activities with the potential to significantly affect all aspects of biodiversity, including those components situated in ABNJ. They depend on a detailed level of knowledge of species, habitats and ecosystems and their interconnections in a particular marine area. A process has also been undertaken in the СBD to define the special considerations to be taken into account in EIAs of activities with the potential to significantly affect biodiversity in marine and coastal areas, including ABNJ. The Conference of the Parties of the CBD has also been proactive in

5 Biodiversity in Impact Assessment. Background Document to Decision VIII/28 of the Convention on Biological Diversity. Voluntary Guidelines on Biodiversity-Inclusive Impact Assessment, http://www.cbd.int/doc/publications/pubcbd-ts-26-en.pdf >. 
investigating the scientific and technical aspects of EIA for activities in ABNJ. It convened an Expert Workshop on Scientific and Technical Elements of the СвD EIA Guidelines which focused on ABNJ in November 2009. ${ }^{6}$ This highlighted some of the governance and practical challenges related to the implementation of EIA for activities in ABNJ.

It emphasised the practical difficulties associated with conducting EIAs including:

- The industry proposing the activity and the national flag State jurisdiction are often far from the marine area affected;

- The conduct of EIA and management, control, monitoring, surveillance and follow-up activity were likely to be more costly and may be less effective for a given budget; and

- Capacity building needs for EIA in ABNJ would be greater as customs of practice are less established, methodologies less mature, and multiple assessment cultures may converge in the same area. ${ }^{7}$

The complex and fragmentary nature of the law and institutions governing ABNJ were accentuated, including:

- The split legal framework for ABNJ - high seas (LOSC Part VII) and deep seabed beyond national jurisdiction - the Area (LOSC Part XI and Part XI Implementation Agreement);

- The diverse institutional framework for ABNJ including States, non-State actors and global and regional organizations and the need for cooperation between all these actors to conserve biodiversity;

- The fact that stakeholders are harder to define for ABNJ because communities do not have immediate proximity to these areas; and

- The variable standards of compliance among states with environmental assessment obligations in international conventions. ${ }^{8}$

The Workshop's Report was considered by the tenth Conference of Parties of the CBD in 2010 which endorsed the development of voluntary guidelines for the consideration of biodiversity in EIAs for marine and coastal areas drawing on the guidance from the Workshop. ${ }^{9}$ Guidelines were then developed for all marine and coastal areas rather than simply for $\mathrm{ABNJ}$ emphasising the

6 Report of the Expert Workshop on Scientific and Technical Aspects relevant to Environmental Impact Assessment in Marine Areas beyond National Jurisdiction, UNEP/CBD/EW-EIAMA/2, 20 November 2009, <http://www.cbd.int/doc/?metting=EWEIAMA-o1 >.

7 Ibid., Annex II, paras. 10-14.

8 Ibid., Annex II, paras. 7-9.

9 Report of the Tenth Meeting of the Conference of the Parties to the Convention on Biological Diversity, UneP/CBD/COP/10/27, 20 January 2011, Annex, Decision x/29, para. 50, <http:// www.cbd.int/copı/doc/>. 
interconnections between ocean ecosystems across jurisdictional boundaries and endorsed by the eleventh Сор of the СвD in $2012 .{ }^{10}$ This initiative represents an important step in defining the special characteristics of EIA for activities in ABNJ and provides an initial repository for scientific and technical information on EIA for all sectors operating in ABNJ.

\subsubsection{Unep Goals and Principles of eia (Unep Principles)}

The 1987 UNEP Principles represent one of the earliest global elaborations of the objectives and fundamental procedures encompassed in EIA. ${ }^{11}$ They provide an internationally accepted model of the minimum requirements for effective EIA. Principle 1 specifies that an EIA should include:

- A description of the proposed activity;

- A description of the potentially affected environment, including specific information necessary for identifying and assessing the environmental effects of the proposed activity;

- A description of the practical alternatives, as appropriate;

- An assessment of the likely or potential environmental impacts of the proposed activity and alternatives, including the direct, indirect, cumulative, short-term and long-term effects;

- An identification and description of measures available to mitigate adverse environmental impacts of the proposed activity and alternatives, and an assessment of those measures;

- An indication of gaps in knowledge and uncertainties that may be encountered in compiling the required information; and

- An indication whether the environment of any other state or of ABNJ are likely to be affected by the proposed activity or alternatives.

The general obligation to consult with interested stakeholders on an EIA before a decision is made to proceed with an activity is recognized in Principle 7 which provides that ".. government agencies, members of the public, experts in relevant disciplines and interested groups should be allowed appropriate opportunity to comment on the EIA." For activities affecting the marine areas of $A B N J$, this immediately raises the question of who qualifies as an interested stakeholder particularly for $\mathrm{ABNJ}$ and which global, regional or

\footnotetext{
10 Report of the Eleventh Meeting of the Conference of the Parties to the Convention on Biological Diversity, UNEP/CBD/COP/11/27, 5 December 2012, Annex, Decision XI/18, p. 7, $<$ http://www.cbd.int/cop/?11=cop-11 $>$.

11 Unep, United Nations Environment Programme Goals and Principles of EIA (UneP Principles) at http://www.unep.org/Documents.Multilingual/Default.asp?DocumentsID=1008ArticleID=1658 (28 April 2012).
} 
national organization is responsible for administering and responding to such consultation.

In relation to decisions or actions taken by the proponent following an EIA, the UNEP Principles adopt a due diligence approach requiring the proponent to fully examine the potential environmental impacts of a particular project or activity and give due consideration to the interests of affected parties but not imposing a particular decision path on the proponent. Although the UNEP Principles do not extend the proponent's obligations beyond this due diligence approach, it could be argued that if an EIA concludes that significant harm is likely to marine areas, under the international law duty to prevent transboundary harm set out in Principle 21 of the Stockholm Declaration and Principle 2 of the Rio Declaration and confirmed by the ICJ in their Advisory Opinion on the Legality of the Threat or Use of Nuclear Weapons, the state conducting such an EIA would be under a positive obligation to mitigate that harm or refrain from the activity. ${ }^{12}$

\subsection{Decisions of International Tribunals}

The process of environmental assessment, particularly EIA, is one of the means by which States can implement a range of international environmental law principles. An EIA plays a fundamental role in discharging States' obligations to prevent transboundary harm, adopt a precautionary approach and promote sustainable development. ${ }^{13}$ The customary international law status of EIA, including its marine components, has been discussed in a number of recent judgments of the International Court of Justice (ICJ) and an advisory opinion of the International Tribunal for the Law of the Sea (ITLOS). In the GabcikcovoNagymaros Case the ICJ considered assessment, notification and consultation, effectively the elements of an EIA process, to be a necessary step in a State's implementation of the duty to prevent transboundary harm and the concept of sustainable development. ${ }^{14}$ In the Pulp Mills Case, the ICJ found that:

12 Declaration of the United Conference on the Human Environment, Stockholm, 16 June 1972 (1972) 11 ILM 1416; Rio de Janeiro Declaration on Environment and Development, Rio de Janeiro, 3 to 14June 1992, UN Doc A/CONF.151/5/REV.1(1992) 31 ILM 876; International Court of Justice, Advisory Opinion on Legality of the Threat or Use of Nuclear Weapons, 8 July 1996, <http://www.icj-cij.org/docket/fi les/95/7495.pdf PHPSESSID=244d61421d993dcdd51859eegc657bıb>, 241-242, para. 29; Neil Craik, The International Law of Environmental Impact Assessment (Cambridge University Press, 2008) 67.

13 Craik, above note 12, 54, 77 and 224.

14 Gabcikovo-Nagymaros Project (Hungary/Slovakia) (1997) ICJ Rep. 7, para. 141; Alan Boyle, "The Gabcikovo-Nagymaros Case: New Law in Old Bottles" (1997) 8 Yearbook of International Environmental Law 18; Craik, above note 12, 114. 
..it may now be considered a requirement under general international law to undertake an environmental impact assessment where there is a risk that the proposed industrial activity may have a significant adverse impact in a transboundary context, in particular, on a shared resource. ${ }^{15}$

In the Mox Plant Case, Itwos concluded that the United Kingdom had breached its obligations under Article 206 of the LOSC by failing to carry out an adequate assessment of the potential impacts of a nuclear fuel reprocessing plant in Cumbria on the marine environment of the Irish Sea. ${ }^{16}$ The 2011 advisory opinion of ITLOS on the "Responsibilities and Obligations of States Sponsoring Persons and Entities with Respect to Activities in the Area" also acknowledged the customary international law status of the obligation to conduct EIAs for activities with the potential for significant impacts on the marine environment, including for ABNJ, specifically the Area. ${ }^{17}$

\subsection{Regional Instruments}

2.3.1 Regional Seas Conventions

There are broad obligations on environmental assessment in most of the UNEP and non-UNEP regional seas agreements, but only a few regional seas programs have specific environmental protection responsibilities for ABNJ areas. ${ }^{18}$ Parties to the regional seas conventions are typically responsible for developing EIA guidelines, legislation and processes that prevent or minimize harmful effects on the Convention Area with the assistance of competent global, regional and sub-regional organizations. The conventions do not incorporate

15 Pulp Mills on the River Uruguay Case (Argentina/Uruguay) (Provisional Measures) (2006) ICJ Rep. para. 204.

16 Mox Plant Case (Provisional Measures) itlos No. 10 (2001), para. 82; Alan Boyle, "Environmental Jurisprudence of the International Tribunal for the Law of the Sea" (2007) 22(3) International Journal for Marine and Coastal Law 377; Marie Cordonnier Segger, Marcus Gehring and Andrew Paul Newcombe, Sustainable Development in World Investment Law (Kluwer Law International, 2011) $15^{2}$.

17 International Tribunal of the Law of the Sea, Advisory Opinion on Responsibilities and Obligations of States Sponsoring Persons and Entities with Respect to Activities in the Area, 1 February 2011, <http://www.itlos.org/fileadmin/itlos/documents/cases/case_no_17/adv_ op_o10211.pdf>, p. 44, para. 145 .

18 The scope of application of the 1986 Convention for the Protection of the Natural Resources and Environment of the South Pacific Region (Noumea Convention), the 1992 Convention for the Protection of the Marine Environment of the North-east Atlantic (ospar Convention) and the 1995 Convention for the Protection of the Marine Environment and the Coastal Region of the Mediterranean (Barcelona Convention) extend to ABNJ. 
screening, scoping and content prescriptions for EIA, leaving this responsibility to the more detailed legislative enactments of their member states. Different versions of the duty to notify and consult on EIAs with other parties and the relevant regional seas organization appear in many of the conventions, but most are relatively loose prescriptions urging rather than obligating states to disseminate results of EIAs and consult with affected parties.

The 1995 Convention for the Protection of the Marine Environment and Coastal Region of the Mediterranean (Barcelona Convention) makes specific mention of notification and consultation among Contracting Parties where activities are likely to have a significant adverse effect on ABNJ. Article 4(3)(c) provides that:

the Contracting Parties shall promote cooperation between and among States in environmental impact assessment procedures related to activities under their jurisdiction or control which are likely to have a significant adverse effect on the marine environment of other States or areas beyond the limits of national jurisdiction on the basis of notification, exchange of information and consultation.

This provision recognizes the mandatory responsibility of Contracting States to protect and preserve the marine environment beyond national jurisdiction in their region.

The ospar Commission established to implement the 1992 Convention for the Protection of the Marine Environment of the North-east Atlantic (OSPAR Convention) is moving towards more collaborative arrangements between competent regional and global authorities for EIA and SEA of activities, plans, programmes and policies affecting ABNJ marine protected areas (MPAs) within the convention's area of responsibility. The OSPAR Ministerial Meeting in 2010 established six MPAs in ABNJ encompassing four seamounts, an area of the deep seabed beyond national jurisdiction in the southern area of the Charlie Gibbs Fracture Zone and an area to the north of the Azores Islands in the Atlantic..$^{19}$ A collective arrangement between OSPAR and global and regional organizations with responsibilities for managing activities such as fisheries, deep seabed mining and ships routeing in these MPAs including the North East Atlantic Fisheries Commission, the International Seabed Authority and the International Maritime Organization is in the course of negotiation. Under

\footnotetext{
19 OSPAR Commission, OSPAR Network of Marine Protected Areas, <http:www.ospar.org/content/content.asp?menu=00700300100011_000ooo_oooooo >.
} 
this arrangement, joint management plans will be prepared for each of the six MPAs including provisions for cooperation on EIAs and SEAs. ${ }^{20}$

\subsubsection{Protocol on Environmental Protection to the Antarctic Treaty} (Madrid Protocol)

The test applied for screening activities for EIA under the Madrid Protocol to the Antarctic Treaty is more complex and multi-layered than many other international instruments and clearly applies to $\mathrm{ABNJ}$, although there are significant exceptions to its application to certain activities. The screening process has three levels - the preliminary assessment, initial environmental evaluation and comprehensive environmental evaluation. ${ }^{21} \mathrm{~A}$ preliminary assessment is carried out at the national level for all activities subject to the Protocol with less than a minor or transitory impact. If an activity has no more than a minor or transitory impact, an initial environmental evaluation must be carried out, and if it has more than a minor or transitory impact, a comprehensive environmental evaluation must be carried out. All activities, both governmental and non-governmental, in the Antarctic treaty area (south of $60^{\circ} \mathrm{S}$ latitude) are subject to these provisions, except for fishing, sealing, whaling and emergency operations as these are covered by other international instruments. ${ }^{22}$

\subsection{Sectoral Frameworks for Environmental Assessment in ABNJ}

The principal sectors of activity in ABNJ, fishing, shipping, and deep seabed mining, have prescribed limited environmental assessment measures for some of their activities, however for some newer activities such as bio-prospecting, already taking place in $\mathrm{ABNJ}$, there are no mandatory environmental impact assessment instruments or processes.

\subsubsection{Fisheries Sector}

Parties to the UN Fish Stocks Agreement must assess the impacts of fishing, other human activities and environmental factors on target stocks and species

20 "Designation and Management of ospar mPAs Beyond National Jurisdiction in the North-East Atlantic," Presentation by Dr. Henning von Nordheim and Tim Packeiser, IUCN/German Federal Agency for Nature Conservation Seminar on the Conservation and Sustainable Use of Marine Biodiversity beyond National Jurisdiction, 3-6 December 2011, Bonn, Germany.

21 Madrid Protocol, Article 8(1); K. Bastmeijer and R. Roura, "Environmental Impact Assessment in Antarctica," in K. Bastmeijer and T. Koivurova, Theory and Practice of Transboundary Environmental Impact Assessment (Martinus Nijhoff Publishers, 2008), 182. 
belonging to the same ecosystem or associated or dependent ecosystems and develop data collection and research programmes to assess the impact of fishing on non-target and associated or dependent species and their environment. ${ }^{23}$ This obligation has been further elaborated in the 2009 FAO International Guidelines for the Management of Deep Sea Fisheries in the High Seas (Deep Sea Fishing Guidelines), which were developed to help states and RFMO s implement a call from the United Nations General Assembly (UNGA) to prevent significant adverse impacts on vulnerable marine ecosystems or not to authorize the bottom fishing activity to proceed (UNGA Resolution 61/ 105 paragraphs $80-91) \cdot{ }^{24}$ Significant adverse impacts are defined as those that compromise ecosystem integrity (i.e., ecosystem structure or function) in a manner that:

(i) impairs the ability of affected populations to repair themselves;

(ii) degrades the long-term natural productivity of habitats; and

(iii) causes, on more than a temporary basis, significant loss of species richness, habitat or community types. ${ }^{25}$

The Guidelines also specify that impacts should be evaluated individually, in combination and cumulatively. ${ }^{26}$ They call for states to conduct assessments of individual bottom fishing activities and to adopt measures to prevent significant adverse impacts on vulnerable marine ecosystems (VMEs). These procedures include identifying areas or features where VMEs are known or likely to occur, identifying the location of fisheries in relation to these areas and features, and then developing data collection and research programmes to assess the impact of fishing on target and non-target species and their environment. ${ }^{27}$ The Guidelines list the characteristics of VME s that should be subject to assessments and give examples of potentially vulnerable species groups, communities and habitats, as well as features that potentially support them. ${ }^{28}$

\subsubsection{Shipping Sector}

In the shipping sector, only a limited number of activities that ships may engage in beyond national jurisdiction, such as dumping of wastes and ocean fertilization, are subject to risk and environmental assessment processes. For

23 UN Fish Stocks Agreement, Articles 5(d) and 6(3)(d).

24 FAO, International Guidelines for the Management of Deep Sea Fisheries in the High Seas, (2009), <http://www.fao.org/docrep/o11/o816t/o816too.htm>.

25 Ibid., 4, para. 17.

26 Ibid.

27 Ibid., 9-11.

28 Ibid., 4, paras.14-16. 
States Parties to the London Convention, dumping of non-prohibited substances is only allowed subject to the requirements of prior environmental impact assessment, permitting and ongoing monitoring set out in Annex III of the Convention. ${ }^{29}$ For States Parties to the London Protocol, dumping of all waste and other matter is prohibited, except for five listed categories of substances the dumping of which is nevertheless subject to the stringent assessment, permitting and ongoing monitoring requirements of Annex 2 of the Protocol. ${ }^{30}$ Any application for a permit to dump these listed substances must be accompanied by an assessment of the sea disposal options, including information on waste characteristics, conditions at the proposed dump site, fluxes and proposed disposal techniques and specifications about the potential effects on human health, living resources, amenities and other legitimate uses of the sea. These assessments can apply to dumping of wastes in marine areas beyond national jurisdiction as well as to areas within national jurisdiction.

A statement adopted by the Scientific Groups of the London Convention and London Protocol in July 2007 "noted with concern the potential for ocean fertilization activities to have negative impacts on the marine environment and human health" and recommended that the parties to the London Convention and London Protocol consider the issue with a view to its regulation. ${ }^{31}$ This statement was endorsed by the States Parties during their joint annual meeting in November 2007 where the parties agreed that while it was the prerogative of each state to consider proposals for ocean fertilization projects on a caseby-case basis in accordance with the Convention and/or Protocol, knowledge about the effectiveness and potential environmental impacts of open ocean fertilization was currently insufficient to justify large scale projects. They also agreed that ocean fertilization fell within their regulatory competence and that they would "further study this issue from scientific and legal perspectives with a view to its regulation." 32

The ongoing discussions in the London Convention/London Protocol Scientific Groups concerning ocean fertilization prompted the Conference of

29 London Convention, Article IV and Annex III, available online: <http://www5.imo.org/ SharePoint/blastDataHelper.asp/data_id\%3016925/LC1972.pdf >.

30 London Protocol. Article 4 and Annex 2, available online: <http://www.austlii.edu.au/au/ other/dfat/treaties/2006/11.html>.

31 LC/LP Scientific Groups, "Statement of Concern Regarding Iron Fertilization of the Ocean to Sequester $\mathrm{CO}_{2}$," Doc. LC-LP.1/Circ.14, 13 July 2007 .

32 International Maritime Organization, Report of the 29th Consultative Meeting of the Contracting Parties to the Convention on the Prevention of Marine Pollution by Dumping of Wastes and Other Matter, 1972 and 2nd Meeting of the Contracting Parties to the 1996 Protocol thereto, IMO Doc. LC29/LP2 (2007). 
the Parties of the Convention on Biological Diversity at their gth meeting in May 2008 to request parties and urge other governments "in accordance with the precautionary approach to ensure that ocean fertilization activities do not take place until there is an adequate scientific basis on which to justify such activities, including assessing associated risks, and a global transparent and effective control and regulatory mechanism is in place for those activities; with the exception of small scale scientific research within national jurisdiction." ${ }^{33}$ An exception was noted in the case of "small scale scientific research studies within coastal waters," which "should only be authorized if justified by the need to gather specific scientific data, and should also be subject to a thorough prior assessment of the potential impacts of the research studies on the marine environment, and be strictly controlled, and not be used for generating and selling carbon offsets or any other commercial purposes." ${ }^{34}$ An intersessional Technical Working Group on Ocean Fertilization was established to develop an Assessment Framework for Scientific Research Involving Ocean Fertilization to provide a mechanism for assessing, on a case-by-case basis, whether proposals for ocean fertilization activities represent legitimate scientific research. ${ }^{35}$ The draft Assessment Framework ${ }^{36}$ was reviewed by the Scientific Groups in June 2009 and adopted as a work in progress. ${ }^{37}$ The draft was tabled again during an extraordinary session of the Scientific Groups in October $2010^{38}$ where further revisions were made and it was adopted, by consensus, in a non-binding resolution at the October 2010 meeting of the parties. ${ }^{39}$ The Assessment Framework (AF) is described as a "tool ... to determine if the proposed activity constitutes legitimate scientific research that is not contrary to the [LC/LP] aims." It sets out a two-stage process involving an initial assessment and an environmental assessment. The purpose of the initial

33 Cop 9 Decision XI/16 on Biodiversity and Climate Change, (Presented at the Ninth Meeting of the States Parties to the Convention on Biological Diversity (Cop 9), Bonn, 19-3o May 20o8) Section $\mathrm{C}$, <http://www.cbd.int/decisions/copg/?m=COP-og\&id=11659\&lg=o $>$ on 27 August 2008.

34 Ibid.

35 LC.3o/16, para. 2.3 .

$36 \quad \mathrm{LC} / \mathrm{SG}^{-\mathrm{CO}_{2}} 3 / 5$, annex 2.

37 LC/SG $32 / 15$, paras. $2.18-2.29$.

38 See Draft Assessment Framework for Scientific research Involving Ocean Fertilization Doc LC/SG/ES.2, 3 o July 2010.

39 32nd Consultative Meeting of Contracting Parties to the Convention on the Prevention of Marine Pollution by Dumping of Wastes and Other Matter, 1972 (London Convention) and 5th Meeting of Contracting Parties to the 1996 Protocol thereto (London Protocol) Assessment Framework for Scientific Research Involving Ocean Fertilization, Resolution LC-LP.2 (2O10). 
assessment is to determine whether the proposed ocean fertilization activity constitutes legitimate scientific research. To qualify as such the proposed activity must have "proper scientific attributes," which means:

1. The proposed activity should be designed to answer questions that will add to the body of scientific knowledge. Proposals should state their rationale, research goals, scientific hypotheses and methods, scale, timings and locations with clear justification for why the expected outcomes cannot reasonably be achieved by other methods;

2. Economic interests should not influence the design, conduct and/or outcomes of the proposed activity. There should not be any financial and/ or economic gain arising directly from the experiment or its outcomes. This should not preclude payment for services rendered in support of the experiment of the future financial impacts of patented technology;

3. The proposed activity should be subject to scientific peer review at appropriate stages in the assessment process. The outcomes of the scientific peer review should be taken into consideration by the Contracting Parties. The peer review methodology should be stated and the outcomes of the peer review of successful proposals should be made publicly available together with the details of the project; and

4. The proponents of the proposed activity should make a commitment to publish the results in peer-reviewed scientific publications and include a plan in the proposal to make the data and outcomes publicly available in a specified time frame.

Proposals that meet these criteria may then proceed to the next stage, the environmental assessment that includes requirements of risk management and monitoring. The environmental assessment stage entails a number of components including the problem formulation, a site selection and description, an exposure assessment, an effects assessment, risk characterization and risk management sections. ${ }^{40}$ Only after completion of the environmental assessment is a decision made on whether the proposed activity constitutes legitimate scientific research that is not contrary to the aims of the London Convention or/London Protocol. If so, the activity is permitted to proceed. In October 2013, the Contracting Parties to the London Convention and London Protocol adopted an amendment to the Protocol which, when it enters into force, will make this risk assessment framework mandatory for all specified marine

40 Assessment Framework for Scientific Research Involving Ocean Fertilization, LC 32/ 15, Annex 6, pp. 5-19, <http://ww.imo.org/SharePoint/blastDataHelper.asp/data id\%3 ${ }_{3}$ 30641/AssessmentFramework-annex6-LC-32-15.pdf >. 
geoengineering activities. ${ }^{41}$ The only marine geoengineering activity specified at this stage is ocean fertilization.

\subsubsection{Deep Seabed Mining Sector}

Deep seabed mining activities in ABNJ are subject to a well-developed framework of environmental assessment obligations. An exploration contractor must submit an assessment of the potential environmental impacts of proposed activities with an application for approval of a plan of work together with a description of proposed measures for the prevention, reduction, and control of possible impacts on the marine environment to the International Seabed Authority (ISA). ${ }^{42}$ The Recommendations for the Guidance of the Contractors for the Assessment of the Possible Environmental Impacts Arising from Exploration for Polymetallic Nodules in the Area, issued by the Authority's Legal and Technical Commission in revised form in 2010, specify the particular activities of exploration contractors that are subject to EIA. ${ }^{43}$ The sponsoring state for an exploration contractor is under a due diligence obligation to ensure that an exploration contractor fulfils all these obligations. ${ }^{44}$

\section{Challenges to Implementing Environmental Assessment in A BNJ}

The governance structures underpinning environmental assessment in marine areas are directly related to the scheme of maritime jurisdiction and different maritime zones prescribed in the Losc. The ability of states to fulfil this obligation in ABNJ is largely dependent on individual flag States supplemented

41 Report of the Working Group on the Proposed Amendment to the London Protocol to Regulate Placement of Matter for Ocean fertilization and other Marine Geo-engineering Activities, LC Doc 35/WP.3, 17 October 2013; Philomène Verlaan, "Current Legal Developments: London Convention and London Protocol” (2011) 26(1) International Journal of Marine and Coastal Law 185-194.

42 Agreement Relating to the Implementation of Part XI of the United Nations Convention on the Law of the Sea of 10 December 1982, opened for signature 28 July 1994, 33 ILM 1309 (entered into force 28 July 1996) ('Part XI Implementation Agreement'), Annex, para. 7; Regulations for Prospecting and Exploration of Polymetallic Nodules (Polymetallic Nodule Regulations), <http://www.isa.org.jm/files/documents/en/Regs/pn-en.pdf>, Regulation 18 (c) and (d).

43 Recommendations for the Guidance of Contractors for the Assessment of the Possible Environmental Impacts Arising from Exploration for Polymetallic Nodules in the Area, http://www.isa.org.jm/files/documents/EN/7Sess/LTC/isba_7ltc_1Revı.pdf, para 10.

44 ItLos Advisory Opinion, above note 17, 43-44, paras. 141-143; Polymetallic Nodules Regulation 31(6) and Polymetallic Sulphides Regulation 33(6). 
by the limited collaborative institutions and mechanisms they have established for environmental assessment in ABNJ. Lack of an integrated system of environmental governance for ABNJ presents considerable problems for implementing comprehensive environmental assessment processes in these vast areas of the ocean. The predominant form of jurisdiction in $\mathrm{ABNJ}$ is flag state jurisdiction. For shipping transiting ABNJ, it falls to individual flag States rather than any regional or global body to regulate and enforce the activities of their flag vessels including their impacts on the marine environment. This results in variable levels of compliance with environmental standards, and no auditing of individual flag State performance or sanctioning of sub-standard performance. Many of the stages in an environmental impact assessment process require coordinating authorities which are conspicuously lacking in the fragmentary and disjunctive system of governance applicable to most ABNJ activities. These stages include the initial screening process to select which activities are subject to environmental assessment, the scoping process to decide the terms of reference for an environmental assessment, the public notification and consultation process to engage relevant stakeholders, the post EIA decision-making phase and the ongoing monitoring of environmental impacts.

\section{Rationale and Objectives for Including EIA Elements in the International Legally Binding Instrument for Conservation and Sustainable Use of Marine Biodiversity in ABNJ (ILBI)}

The ввNJ Working Group which preceded the Intergovernmental Conference negotiating the ILBI discussed reasons for including EIA as one of the key components in any future Implementing Agreement on the Conservation and Sustainable Use of Marine Biodiversity in Areas beyond National Jurisdiction. ${ }^{45}$ A key plank of the rationale for including EIA elements is to capture activities occurring in ABNJ that are not already subject to sectoral EIA processes, in effect, to provide a default EIA system for activities such as bio-prospecting and marine geoengineering. Another reason for including EIA elements is to provide best practice standards for EIA in ABNJ where scientific knowledge of marine biodiversity is still nascent. Developing best practice standards for EIA in ABNJ may well entail the incorporation of new elements into the generally

45 Letter from the Co-Chairs of the Ad Hoc Open-ended Informal Working Group to study issues related to the conservation and sustainable use of marine biodiversity in areas beyond national jurisdiction to the President of the General Assembly, 30 June 2011, Annex, Section I, paras. (a) and (b). 
accepted components of the EIA process. Rather than perpetuating a situation where EIA is simply a procedural hurdle for the proponents of a particular activity, a best practice standard could require a process that is biodiversity inclusive, transparent and subject to international scrutiny with associated powers to impose conditions in the interest of mitigating adverse impacts on the marine environment or to disallow the activity where there is the potential for substantial harm to the marine environment.

Typical components of an EIA process include screening, scoping of the terms of reference for an EIA, public notification and consultation, reporting and post-report decisions on whether to impose conditions on the activity or to disallow it. ${ }^{46}$

\subsection{Screening}

The screening component of an EIA process determines whether particular activities or projects will be subject to an EIA. The threshold of significant effects on the environment as the trigger for subjecting activities to EIA has gained wide acceptance in global and regional instruments as well as national legislation. ${ }^{47}$ The Environmental Protocol to the Antarctic Treaty (Madrid Protocol) is a notable exception to this generally accepted threshold with the screening process involving three levels - the preliminary assessment level, the initial environmental evaluation level and the comprehensive environmental evaluation level. A preliminary assessment is carried out at the national level for all activities subject to the Protocol with less than a minor or transitory impact. ${ }^{48}$ If an activity will have no more than a minor or transitory impact, an initial environmental evaluation must be carried out at the national level..$^{49}$ If it has more than a minor or transitory impact, a comprehensive environmental evaluation must be carried out and submitted to the Committee on Environmental Protection (CEP) of the Madrid Protocol. ${ }^{50}$ This is a potential option for screening thresholds in $\mathrm{ABNJ}$, at least for activities intended to occur in

\footnotetext{
46 Craik, above note $12,132$.

47 Ibid., 133 .

48 Madrid Protocol, Annex I, art.1(1).

49 Ibid., Annex I, arts. 2(1) and 3(1).

$50 \quad$ Ibid., Annex I, $\operatorname{art.3(2)}$.
} 
sensitive areas of the $\mathrm{ABNJ}$ environment such as identified vulnerable marine ecosystems (VMES) and ecologically and biologically significant areas (EBSAs).

In addition to threshold criteria, many EIA regimes list activities which will automatically be subject to EIAs and criteria to assist in determining which other activities should be subject to EIA s. ${ }^{51}$ An indicative list of such activities for ABNJ would include deep sea fishing, aquaculture, dumping of waste, marine geoengineering, offshore hydrocarbon production, bio-prospecting, marine scientific research, laying of submarine cables and pipelines, ballast water exchange, deep sea tourism expeditions and ocean energy operations. Criteria to assist States in determining which other activities should be subject to EIAs could be modelled on the СвD Voluntary Guidelines for BiodiversityInclusive EIA, ${ }^{52}$ particularly as the proposed international agreement will relate to conservation and sustainable use of biodiversity in ABNJ. These might include whether:

- The proposed activity is located in or close to an area of special environmental sensitivity or representative international importance;

- The intended activity would affect the biophysical environment directly or indirectly in such a manner that it will increase risks of extinction of genotypes, cultivars, varieties, populations of species or increase the chance of loss of habitat or ecosystems;

- The intended activity would surpass the maximum sustainable yield i.e. the carrying capacity of a habitat/ecosystem or the maximum allowable disturbance level of a resource, population or ecosystem; and/or

- The proposed activity would have particularly complex and potentially adverse effects including those giving rise to serious effects on valued species or organisms or those which threaten the existing or potential use of an affected area.

\section{$5.2 \quad$ Scoping}

Once the need for an EIA has been agreed, a scoping process follows that determines the focus, depth and terms of reference for the EIA. The fundamental objective of the scoping process is to identify those issues arising from the proposed activity which are most likely to have a significant impact on the environment and to describe alternatives that avoid, mitigate, or compensate for adverse impacts on the environment. The content of the EIA report or

$5^{1}$ Craik, above note 12, 134-135.

52 Biodiversity in Impact Assessment. Background Document to Decision VIII/28 of the Convention on Biological Diversity. Voluntary Guidelines on Biodiversity-Inclusive Impact Assessment, <http://www.cbd.int/doc/publications/pubcbd-ts-26-en.pdf>. 
Environmental Impact Statement (EIS) is derived on the basis of these elements. The scoping stage of EIAs for activities in ABNJ while addressing the same issues could also incorporate examination of impacts and alternatives which take into account the shared interests of the international community such as the long term sustainability of marine resources, continuing marine scientific research and the stability of global climate.

\subsection{Reporting}

The EIS which is usually prepared by the proponent of the activity forms the basis for subsequent decisions by the relevant authorities on whether an activity should proceed and whether conditions should be imposed on the activity. The potential elements of an EIS for proposed activities in ABNJ could include:

- A description of the proposed activity including its purpose, location, duration and intensity;

- A description of the initial environmental reference state and a prediction of the future environmental reference state in the absence of the proposed activity;

- A description of the programme for oceanographic and environmental baseline studies that would enable an assessment of the potential environmental impact including but not restricted to the impact on biodiversity of the proposed activity;

- A description of the practical alternatives, including the alternative of not proceeding and the consequences of those alternatives;

- An assessment of the likely or potential environmental impacts of the proposed activity and alternatives, including the direct, indirect, individual and combined, cumulative, short-term and long-term effects of the proposed activity and alternatives in the light of existing and known planned activities;

- A description of the expected biophysical changes resulting from proposed activities, including a description of ecosystems lying within the range of influence of such changes and the spatial and temporal scale of influence of each biophysical change, identifying effects or connectivity between ecosystems, and potential cumulative effects;

- A determination of whether there will be adverse impacts on biodiversity or ecosystems affected by the expected biophysical changes in terms of composition, structure (spatial and temporal) and key processes highlighting any irreversible impacts and irreplaceable loss;

- Identification, in consultation with the scientific and technical advisory body to the Conference of the Parties (COP) of the Implementing Agreement of the current and potential ecosystem services provided by the 
affected ecosystems and determination of the values these represent for the international community highlighting any irreversible impacts and irreplaceable loss;

- As complete a consideration as possible of effects involving impediments to migration, of transboundary effects on migratory species and of impacts on migratory patterns or migratory ranges;

- Definition of possible alternatives, including "no net biodiversity loss" or "biodiversity restoration" alternatives and location, scale, siting, lay out and technology alternatives;

- An assessment in consultation with the Intergovernmental Panel on Climate Change (IPCC) of the likely impacts on global climate of the proposed activity, whether positive or negative;

- A description of the methods, data and underlying assumptions used to forecast the impacts of the proposed activity;

- An identification and description of measures available to prevent or avoid adverse environmental impacts of the proposed activity and alternatives and an assessment of those measures;

- A description of the effects of the proposed activity on the conduct of scientific research and on other existing uses and values;

- An identification of whether the proposed activity will affect the proponent's compliance with its obligations under customary or conventional international law;

- An identification of gaps in knowledge and uncertainties encountered in compiling the information required for the EIA report; and

- A non-technical summary of the information provided under the previous clauses.

\subsection{Public Notification and Consultation}

The duty to notify and consult with affected parties is an integral component of environmental impact processes in both the national and transboundary arenas. $^{53}$ The general obligation to notify and consult, derived from the international law duty to cooperate and found in a variety of hard and soft law instruments, can be adapted to activities in ABNJ. When information provided as part of an EIA indicates that the environment of ABNJ is likely to be significantly affected by a proposed activity, the proponent of the activity being planned should notify and consult with potentially affected stakeholders and provide them with relevant information. In the ABNJ context, potential stakeholders 
could include States, members of the public, international and regional organizations, inter-governmental and nongovernmental organizations, industry representatives and corporate entities. Before a decision is made on whether activity proceeds and on what conditions, these stakeholders should be provided with an opportunity to comment. To assist in this process, States could be encouraged to notify other States and competent international organizations of planned activities under their jurisdiction or control which may have a significant effect on marine biodiversity in ABNJ. There is also the potential for a more enhanced role for the regional seas organizations as dissemination points and consultation hubs on EIAs and as technical advisers on mitigation measures.

\subsection{Post EIS Decision-Making}

Under most EIA regimes, the obligation on the final decision-maker is one of due diligence encompassing a full examination of the potential environmental impacts of a particular project and due consideration for the interests of affected parties. ${ }^{54}$ The global commons status of biodiversity in ABNJ calls for a more stringent and inclusive standard of decision making on whether an activity should be allowed to proceed and on what conditions. This could involve developing a further set of criteria related to the permissible levels of impact on marine biodiversity in $\mathrm{ABNJ}$ and a decision-making structure which involves a level of international scrutiny over EIAs prepared by proponents of particular activities.

\section{Links between EIA Elements and Other Components of the} International Agreement

The EIA components of the ILBI should be consistent with the overarching objectives and general principles articulated in the agreement. For example, the EIA process prescribed in the agreement should be focused on the conservation and sustainable use of marine biodiversity in ABNJ. The institutional infrastructure required for the EIA process prescribed in the ILBI should utilise as far as possible existing global and regional organisations with the relevant expertise as well as the institutions of the international agreement itself. For example, the Conference of the Parties (COP) of the international agreement advised by a Subsidiary Scientific and Technical Body could function as the 
decision-making body for EIAs. Its functions would include setting standards for best practice EIA and reviewing EIAs undertaken by sectoral bodies for activities in ABNJ. It could have powers to impose conditions or disallow activities based on criteria developed around thresholds for adverse impacts on marine biodiversity in ABNJ. The Subsidiary Scientific and Technical Body and the COP could also function as default review and decision-making bodies for EIAS of new and emerging activities in ABNJ not covered by existing sectoral EIA regimes. In addition, the EIA screening criteria developed under an international agreement should take into account any network of MPAs designated by the COP of the agreement.

\section{$7 \quad$ Conclusions}

The obligation to identify the environmental impacts of human activities and to mitigate their adverse effects is equally critical to combating these threats to biodiversity in $\mathrm{ABNJ}$ as it is in marine areas under national jurisdiction. While legal and institutional frameworks for environmental assessment are well established in many countries for marine areas under national jurisdiction, collaborative structures and mechanisms to achieve the same objectives in $\mathrm{ABNJ}$ are still fragmentary and underdeveloped. Establishing these governance structures in $\mathrm{ABNJ}$ is a much more complicated endeavour involving multiple stakeholders including states, global and regional organizations, marine industries and non-governmental organizations focussed on protecting the marine environment. The negotiation of an international agreement for the conservation and sustainable use of marine biodiversity in ABNJ offers the opportunity to develop best practice standards for a biodiversity-inclusive EIA for all activities with the potential for adverse impacts on the marine biodiversity of ABNJ. With appropriate elaboration and adaptation from existing EIA regimes, it can provide a process for assessing the impacts of previously unexamined activities in ABNJ and new and emerging activities. An EIA regime for ABNJ also provides an opportunity for the shared interests of the international community in conserving and sustainably using marine biodiversity to be represented in a transparent and inclusive process which takes into account the interests of multiple ocean stakeholders of current and future generations. The development of an EIA regime for ABNJ is a fundamental prerequisite for the conservation and sustainable use of marine biodiversity across the whole spectrum of ABNJ activities. 